Case Report

\title{
Massive Acute Spinal Subdural Hematoma Causing Sudden Onset Paraplegia in a Patient on Anticoagulation
}

\author{
Jacob Kosarchuk $\mathbb{D}^{1}{ }^{1}$ Courtney Lewis, ${ }^{2}$ and Martin H. Pham $\mathbb{D}^{2}$ \\ ${ }^{1}$ Eastern Virginia Medical School, Norfolk, Virginia, USA \\ ${ }^{2}$ Department of Neurosurgery, University of California San Diego School of Medicine, San Diego, California, USA
}

Correspondence should be addressed to Martin H. Pham; martinpham@gmail.com

Received 7 April 2020; Accepted 28 October 2020; Published 16 November 2020

Academic Editor: Giovanni Mariscalco

Copyright (c) 2020 Jacob Kosarchuk et al. This is an open access article distributed under the Creative Commons Attribution License, which permits unrestricted use, distribution, and reproduction in any medium, provided the original work is properly cited.

\begin{abstract}
Spinal subdural hematoma (SSDH) is a rare but known entity that can cause severe and irreversible motor, sensory, and autonomic dysfunction if not decompressed in a timely manner. We present here a 74-year-old female on anticoagulation who developed sudden onset back pain with rapidly progressive paraplegia. On neurologic exam, she was completely flaccid in the bilateral lower extremities with absent sensation from the umbilicus down. Imaging demonstrated a massive extra-axial spinal hematoma from T12 to S1 that initially was believed to be epidural in origin. She was taken emergently to the operating room for a T11-L5 decompressive laminectomy, and dural opening demonstrated a thick subdural clot encasing the conus and cauda equina confirming the subdural pathology. Despite decompression and partial evacuation of the subdural hematoma, she did not recover neurologic function.
\end{abstract}

\section{Introduction}

Spinal subdural hematoma (SSDH) is a rare but known entity that can cause severe and irreversible sensorimotor and autonomic dysfunction if not decompressed in a timely manner [1-4]. We report here a case of a massive thoracolumbar SSDH in the setting of therapeutic anticoagulation causing acute-onset paralysis.

\section{Literature Search}

A literature search was performed to determine if SSDHs of this size and severity of symptoms were reported elsewhere. We searched PubMed using the terms "spinal subdural hematoma," "massive spinal subdural hematoma," "acute spinal subdural hematoma," with the qualified "AND anticoagulation," "AND warfarin," "AND heparin," "AND aspirin," "AND apixaban," "AND rivaroxaban," "AND dabigatran," with article-type filters for case reports, clinical studies, clinical trials, comparative studies, observational studies, reviews, and systematic reviews. We also performed reviews of citations within articles we found. Our initial search yielded 1,066 articles. After filtering for atraumatic or nonprocedural SSDH, we found 202 articles. Those that did not reference an anticoagulant in the title or body of the article were excluded, leaving a total of 24 articles.

\section{Case Report}

We present here a 74-year-old female on anticoagulation who developed sudden onset back pain and rapidly progressive flaccid paraplegia. On neurologic exam, she was completely flaccid in the bilateral lower extremities with absent sensation from the umbilicus down. Magnetic resonance imaging (MRI) demonstrated a massive ventral spinal subdural hematoma from T12 to S1 (Figure 1). Due to these findings, she was taken emergently to the operating room for decompression and evacuation.

\section{Operation}

A T11-L5 laminectomy was performed for complete epidural decompression. Dural opening demonstrated a thick subdural clot encasing the conus and cauda equina (Figure 2). 


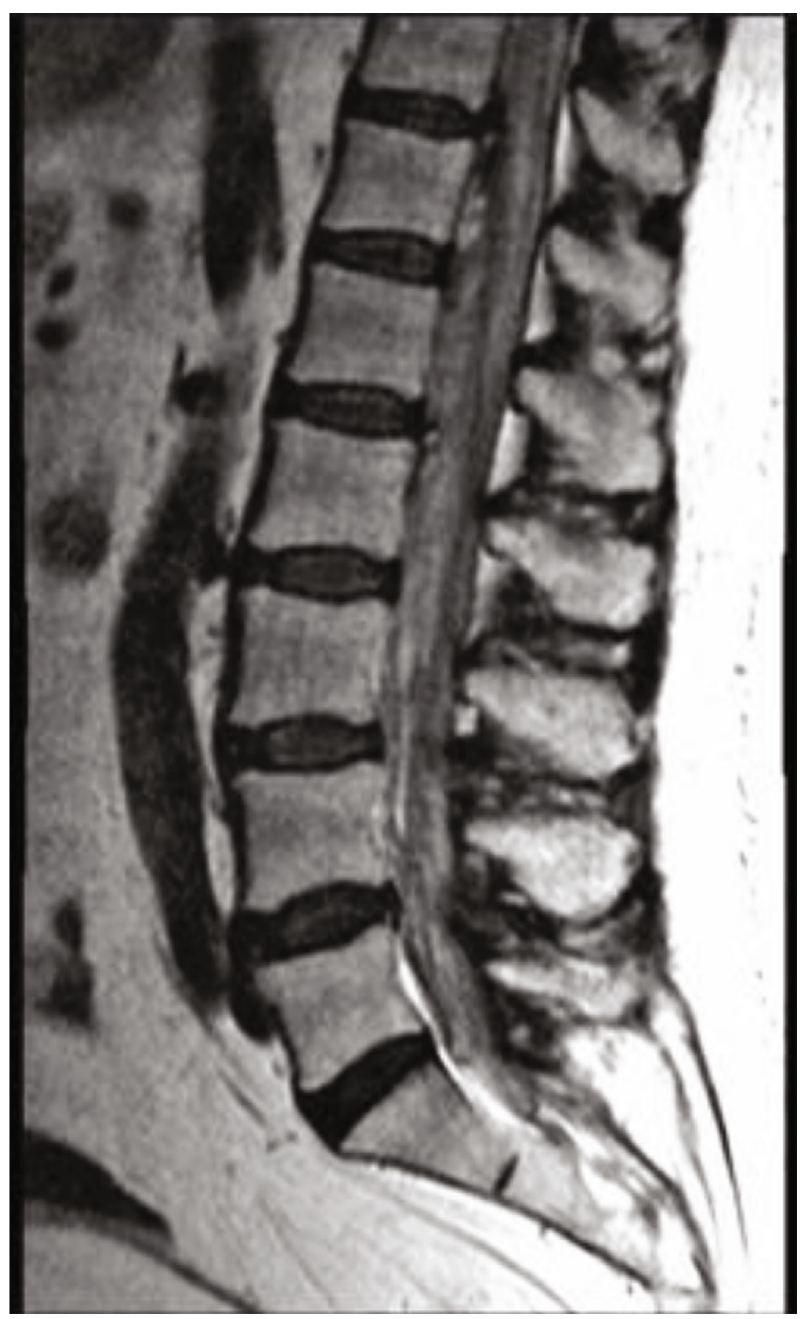

Figure 1: T2-weighted MRI of the lumbar spine demonstrating ventral hypointensity relative to CSF, compressing the conus and cauda equina.

A partial evacuation was performed focusing on the proximal hematoma at the spinal cord and conus; the rest of the clot distal at the cauda equina was partially removed with a combination of direct evacuation and irrigation due to the difficult consistency of the clot encasing the cauda equina roots.

\section{Postoperative Course}

Postoperatively, she did not have any recovery of strength or sensation. She was monitored as an inpatient for 3 days and subsequently discharged to an acute rehabilitation center. At six months follow-up, there has been no recovery of neurologic function.

\section{Literature Review Results}

Our review of the literature resulted in 202 articles discussing atraumatic and nonprocedural iatrogenic SSDH. They included case reports, reviews on management of SSDH, and reviews on imaging diagnosis of SSDH. We found 24 case reports on SSDH in patients who had been anticoagu- lated (Table 1). There was an even distribution of male and female patients ( 12 males and 12 females) found in this literature review, and the average age was 63.06 years with a range of 38 to 80 years old (Table 2). The majority of patients in the series had atrial fibrillation as a comorbidity (15/24), with others including stroke $(2 / 24)$, cardiovascular and disease $(3 / 24)$, venous thromboembolism $(2 / 24)$, cardiac valve replacement $(2 / 24)$, and other $(1 / 24) .2 / 24$ were on low molecular weight heparin (LMWH), 4/24 were on aspirin (in combination therapies), 10/24 were on warfarin, 2/24 were on clopidogrel, 1/24 was on ticlodipine, $3 / 24$ were on apixaban, 4/24 were on rivaroxaban, and 1/24 was on dabigatran. 13/24 patients had multilevel or diffuse SSDH, 9/24 were confined to the thoracic region and 1/24 to the lumbar region, and none had purely cervical or sacral SSDH. 19/24 had no associated subarachnoid hemorrhage (SAH), 4/24 had definite $\mathrm{SAH}$, and $1 / 24$ had indeterminate $\mathrm{SAH}$. 5/24 patients did not improve, $13 / 24$ partially improved, 5/24 fully recovered, and 1 patient died of a cardiac arrest. 16/24 patients received operative intervention, and 8/24 received conservative treatment (including the patient that died). Of the patients that did not improve, all 5 underwent surgical intervention. 10/13 in the partial improvement had surgery compared to $3 / 13$ who were managed conservatively. $4 / 5$ patients who fully recovered were managed conservatively, and $1 / 5$ was operated on.

\section{Discussion}

We present the case of a massive spinal subdural hematoma in an elderly female on anticoagulation causing severe back pain and rapid-onset paraplegia. SSDH as an entity has been previously described, including in association with anticoagulation. We report here a unique case of a massive thoracolumbar SSDH that initially was believed on radiological review to be a ventral epidural hematoma in origin.

Spontaneous spinal subdural hematoma ( $\mathrm{SSSDH})$ is a rare cause of back pain, paraplegia, and cauda equina syndrome and should be considered in a patient who is on anticoagulation, and no other precipitating events are identified [3]. The average age of patients in this case series was 63.06 years (note-one study simply reported the age as "middle aged"), which is similar to a recent study by Pereira et al. but differs from other older studies [3,4]. We found an even distribution of males $(50 \%)$ and females $(50 \%)$ in this case series, which is similar to previously reported rates $[1,4]$. The majority of patients in this series were on warfarin [514], which could be due to a higher rate or longer duration of warfarin use compared to newer novel oral anticoagulants (NOACs) and not necessarily due to the agent itself, though studies have shown lower rates of (unspecified) major bleeding events with NOACs [15-23]. We identified fewer patients on other agents (including antiplatelet therapies) that developed SSDH [14, 24-28].

SSDHs are often associated with coagulopathies (iatrogenic or related to impaired innate hemostasis mechanisms) and procedural iatrogenic causes, though there is still a significant amount of SSDHs secondary to arteriovenous malformations, trauma, and idiopathic causes $[3,4,6]$. The pathophysiology 


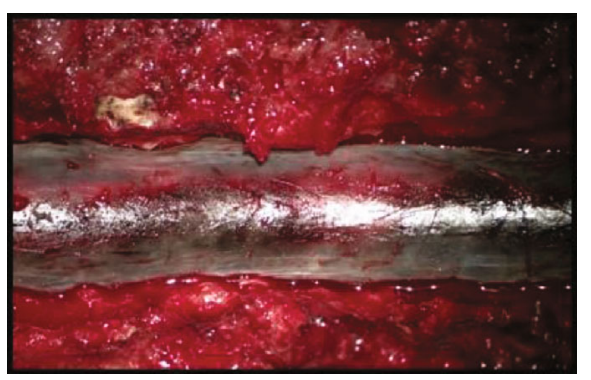

(a)

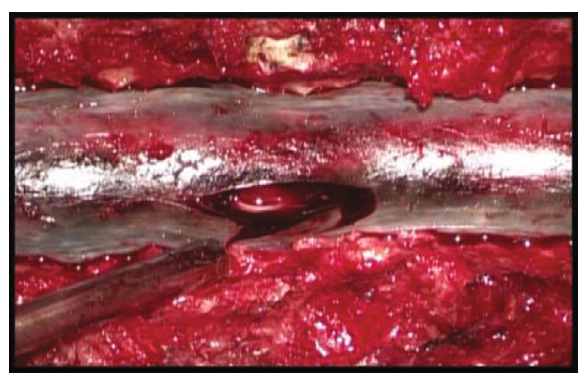

(c)



(b)

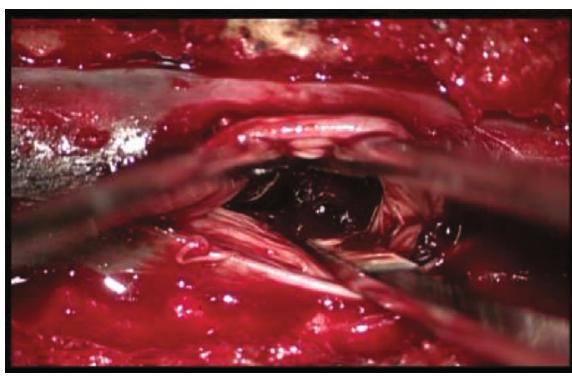

(d)

FIGURE 2: Operative microscope views of the dorsal thoracolumbar spinal dura. Note the mottled appearance of the dural sac (a). Opening of the dural sac (b, c) demonstrates thick clotted blood intradurally. The massive volume of the subdural blood has filled the intradural space and obliterated all egress of cerebrospinal fluid (d).

TABLE 1: Results and summary of the case reports identified in the literature search.

\begin{tabular}{|c|c|c|c|c|c|c|c|c|}
\hline \multicolumn{9}{|c|}{ Patient characteristics } \\
\hline \multirow{2}{*}{ Sex } & Male & Female & & & & & & \\
\hline & 12 & 12 & & & & & & \\
\hline \multirow{2}{*}{ Age } & Average & Min & $\operatorname{Max}$ & & & & & \\
\hline & 63.06 & 38 & 80 & & & & & \\
\hline \multirow{2}{*}{ Comorbidities } & A-fib & Stroke & CVD & $\mathrm{PE} / \mathrm{DVT}$ & $\begin{array}{c}\text { Valve } \\
\text { replacement }\end{array}$ & Other & & \\
\hline & 15 & 2 & 3 & 2 & 2 & 1 & & \\
\hline \multirow{2}{*}{ Agent used } & LMWH & ASA & Warfarin & Clopidogrel & Ticlodipine & Apixaban & Rivaroxaban & Dabigatran \\
\hline & 2 & 4 & 10 & 2 & 1 & 3 & 4 & 1 \\
\hline \multirow{2}{*}{ Location of bleed } & Cervical & Thoracic & Lumbar & Sacral & Multilevel & & & \\
\hline & 0 & 9 & 1 & 0 & 13 & & & \\
\hline \multirow{2}{*}{ Associated SAH } & Yes & No & Indeterminate & & & & & \\
\hline & 19 & 4 & 1 & & & & & \\
\hline \multirow{2}{*}{ Intervention } & Operative & Nonoperative & & & & & & \\
\hline & 16 & 8 & & & & & & \\
\hline \multirow[t]{2}{*}{ Recovery } & $\begin{array}{c}\text { No } \\
\text { improvement }\end{array}$ & $\begin{array}{c}\text { Some } \\
\text { improvement }\end{array}$ & Full recovery & Death & & & & \\
\hline & 5 & 13 & 5 & 1 & & & & \\
\hline \multirow{3}{*}{$\begin{array}{l}\text { Recovery vs. } \\
\text { intervention }\end{array}$} & \multicolumn{2}{|c|}{ No improvement } & \multicolumn{2}{|c|}{ Some improvement } & \multicolumn{2}{|c|}{ Full recovery } & \multicolumn{2}{|c|}{ Death } \\
\hline & Op & Non-Op & Op & Non-Op & Op & Non-Op & Op & Non-Op \\
\hline & 5 & 0 & 10 & 3 & 1 & 4 & 0 & 1 \\
\hline
\end{tabular}

of spontaneous SSDH is still unclear but is theorized to be caused by bleeding within the subdural space itself or as an extension of a subarachnoid bleed into the subdural space after an increase in intrathoracic or intra-abdominal pressure $[1,3]$. Indeed, there have been cases of concomitant SAH and SSDH
$[7,9,14,18,21]$. Important prognostic factors include neurologic status at presentation, presence of coagulopathy, performance of lumbar puncture, and associated diseases [4]. Interestingly, extension of hematoma, surgery, and presence of SAH were not found to be significant predictors of outcome. 


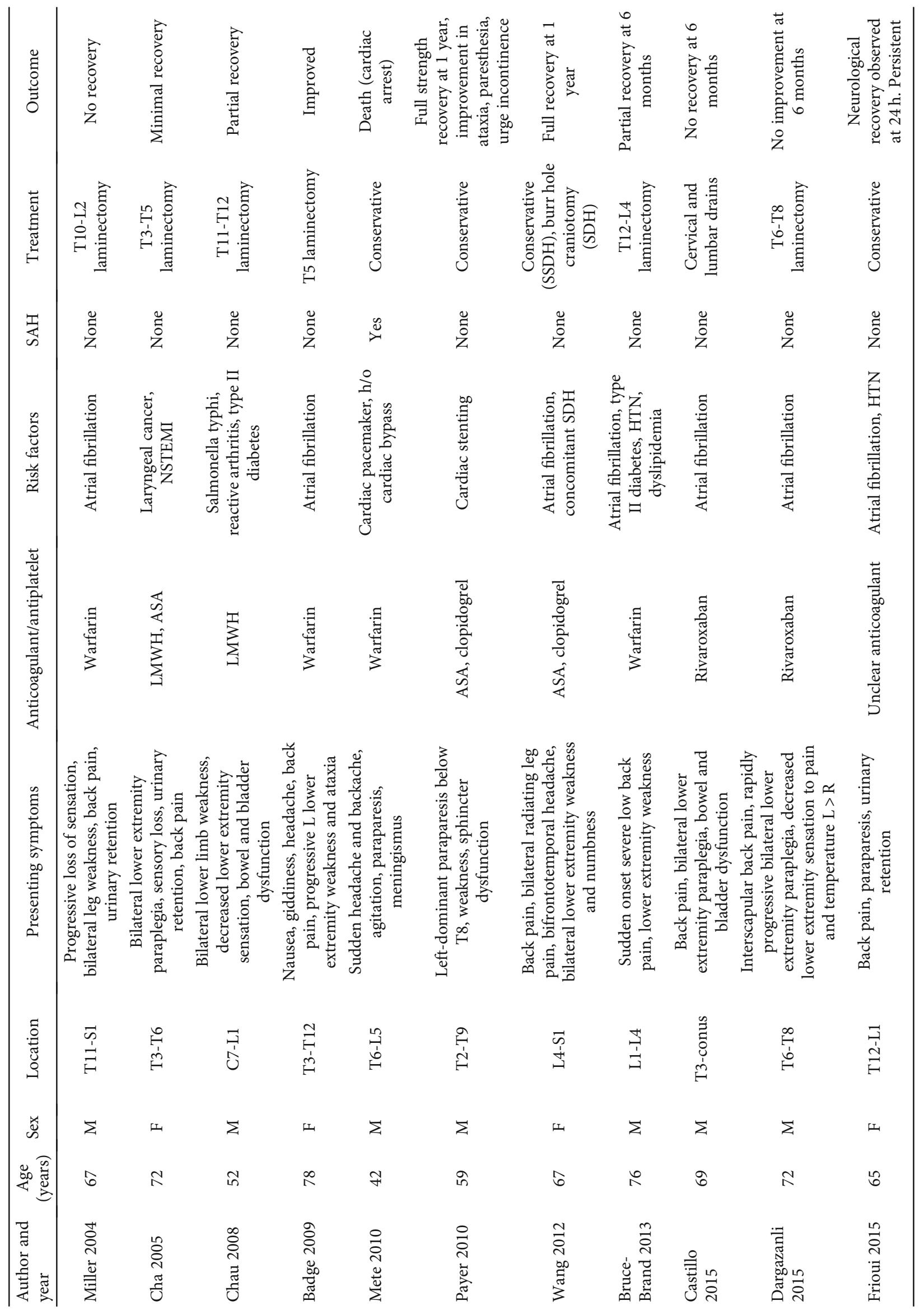




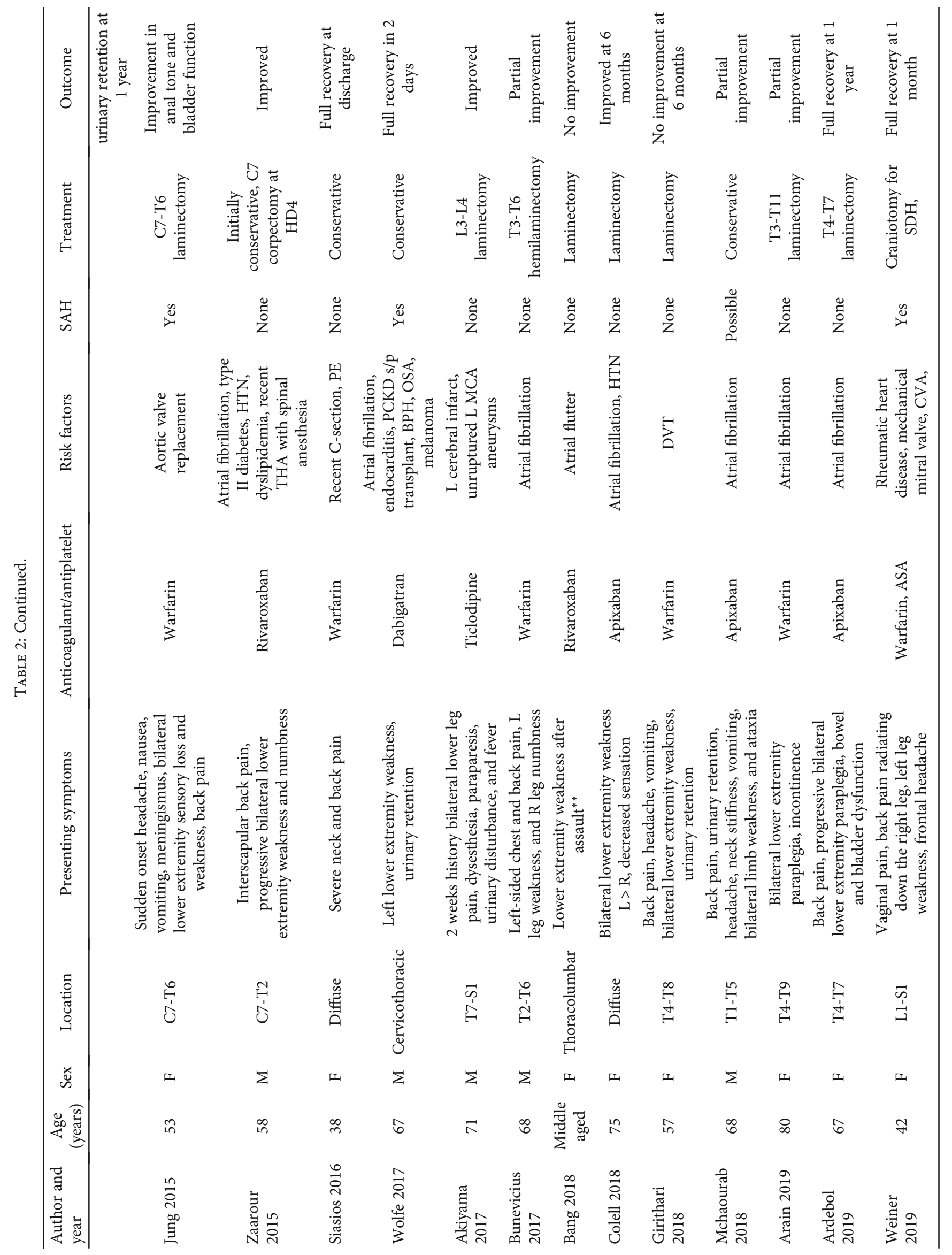




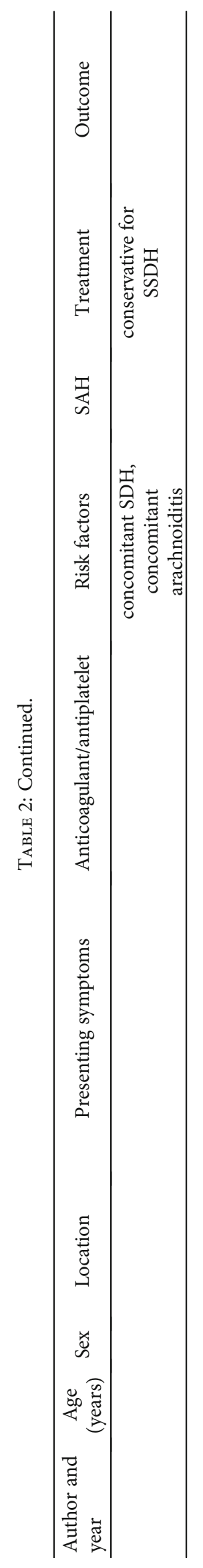


MRI is considered the gold standard in the diagnosis of SSDH, but digital subtraction angiography may be useful if spinal AVM is suspected [2]. SSDH can be managed conservatively with medical management (often including steroids), percutaneous drainage, and surgical evacuation [3, 29]. Though the literature suggests that conservative management results in better outcomes, this may be related to bias in choosing patients with less severe symptoms for medical management whereas more impaired patients are selected for surgical intervention [4].

\section{Conclusion}

SSDH is a rare but serious cause of rapid-onset back pain, sensorimotor, and autonomic deficits, and in some cases, mortality. It is often associated with iatrogenic causes including anticoagulation (as in this case) but in some instances may be idiopathic. MRI is the gold standard for diagnosis. Patients with mild or moderate symptoms can be managed conservatively, but urgent surgical decompression and clot evacuation are warranted in patients with severe symptoms to prevent permanent neurologic injury or death.

\section{Data Availability}

The imaging and photographic data used to support the findings of this study are included within the article.

\section{Conflicts of Interest}

The authors declare that they have no conflicts of interest.

\section{Authors' Contributions}

J. Kosarchuk contributed to the writing, editing, and study design. C. Lewis contributed to the writing and editing. M. Pham contributed to the editing, supervision, acquisition of the data, and study concept.

\section{References}

[1] L. A. Rettenmaier, M. T. Holland, and T. J. Abel, “Acute, nontraumatic spontaneous spinal subdural hematoma: a case report and systematic review of the literature," Case Reports in Neurological Medicine, vol. 2017, 12 pages, 2017.

[2] M. J. Post, J. L. Becerra, P. W. Madsen et al., "Acute spinal subdural hematoma: MR and CT findings with pathologic correlates," American journal of neuroradiology, vol. 15, 1994.

[3] M. Domenicucci, A. Ramieri, P. Ciappetta, and R. Delfini, "Nontraumatic acute spinal subdural hematoma: report of five cases and review of the literature," Journal of Neurosurgery, vol. 91, 1 Suppl, pp. 65-73, 1999.

[4] B. J. A. Pereira, A. N. de Almeida, V. M. F. Muio, J. G. de Oliveira, C. V. M. de Holanda, and N. C. Fonseca, "Predictors of outcome in nontraumatic spontaneous acute spinal subdural hematoma: case report and literature review," World Neurosurgery, vol. 89, pp. 574-577.e7, 2016.

[5] D. R. Miller, A. Ray, and M. D. Hourihan, "Spinal subdural haematoma: how relevant is the INR?," Spinal Cord, vol. 42, no. 8, pp. 477-480, 2004.
[6] R. Badge and D. Chan, "Spinal subdural haematoma in association with anticoagulant therapy, an unusual presentation: a case report and review of literature," Cases Journal, vol. 2, no. 1, p. 151, 2009.

[7] A. Mete, I. Erkutlu, A. Akcali, and A. Mete, "Simultaneous cranial subarachnoid hemorrhage and spinal subdural hematoma," Turkish Neurosurgery, vol. 22, no. 3, pp. 349-352, 2012.

[8] R. A. Bruce-Brand, G. C. Colleran, J. M. Broderick et al., "Acute nontraumatic spinal Intradural hematoma in a patient on warfarin," The Journal of Emergency Medicine, vol. 45, no. 5, pp. 695-697, 2013.

[9] H.-S. Jung, I. Jeon, and S. W. Kim, "Spontaneous spinal subdural hematoma with simultaneous cranial subarachnoid hemorrhage," Journal of Korean Neurosurgical Society, vol. 57, no. 5, pp. 371-375, 2015.

[10] I. Siasios, K. Vakharia, K. Gibbons, and V. Dimopoulos, "Large, spontaneous spinal subdural-epidural hematoma after epidural anesthesia for caesarean section: conservative management with excellent outcome," Surgical Neurology International, vol. 7, p. 664, 2016.

[11] A. Bunevicius, A. Tamasauskas, and K. Ambrozaitis, "Spontaneous thoracic subdural hematoma associated with warfarin therapy: case report with serial MRI," Surgical Neurology International, vol. 10, no. 1, p. 28, 2019.

[12] G. Girithari, I. Coelho dos Santos, T. Alves, E. Claro, M. Kirzner, and A. Massano, "Spontaneous spinal intradural haematoma in an anticoagulated woman," European Journal of Case Reports in Internal Medicine, vol. 1, 2018.

[13] A. R. Arain, M. Moral, S. Shams, K. Desai, and K. Kalsa, “Atypical presentation of atraumatic spinal subdural hematoma associated with warfarin: a case report and review of the literature," Case Reports in Orthopedics, vol. 2019, 4 pages, 2019.

[14] L. A. Weiner, A. C. Richardson, and S. Z. Tewelde, "Spontaneous intracranial and lumbar subdural hematoma presenting as vaginal pain," The Journal of Emergency Medicine, vol. 56, no. 4, pp. e43-e46, 2019.

[15] J. M. Castillo, H. F. Afanador, E. Manjarrez, and X. A. Morales, "Non-traumatic spontaneous spinal subdural hematoma in a patient with non-valvular atrial fibrillation during treatment with rivaroxaban," American Journal of Case Reports, vol. 16, pp. 377-381, 2015.

[16] C. Dargazanli, N. Lonjon, and G. Gras-Combe, "Nontraumatic spinal subdural hematoma complicating direct factor Xa inhibitor treatment (rivaroxaban): a challenging management," European Spine Journal, vol. 25, no. S1, pp. 100-103, 2016.

[17] M. Zaarour, S. Hassan, N. Thumallapally, and Q. Dai, "Rivaroxaban-induced nontraumatic spinal subdural hematoma: an uncommon yet life-threatening complication," Case Reports in Hematology, vol. 2015, 5 pages, 2015.

[18] A. R. Wolfe, R. M. Faroqui, G. A. Visvikis, M. T. Mantello, A. B. Perel, and S. O. Tewari, "Spinal subarachnoid and subdural hematoma presenting as a Brown-Séquard-like myelopathy following minor trauma in a patient on dabigatran etexilate," Radiology Case Reports, vol. 12, no. 2, pp. 257-260, 2017.

[19] W.-S. Bang, K. T. Kim, M. K. Park, J. K. Sung, H. Lee, and D. C. Cho, "Acute spinal subdural hematoma in a patient taking rivaroxaban,” Journal of Korean Medical Science, vol. 33, no. 5, 2018.

[20] A. Colell, A. Arboix, F. Caiazzo, and E. Grivé, "Iatrogenic spinal subdural hematoma due to apixaban: a case report and review of the literature," Case Reports in Hematology, vol. 2018, 5 pages, 2018. 
[21] A. Mchaourab, G. Y.-H. R. Evans, and R. Austin, "Spontaneous spinal subdural haematoma in a patient on apixaban," BMJ Case Reports, vol. 12, no. 1, article e227311, 2019.

[22] J. Zhu, G. C. Alexander, S. Nazarian, J. B. Segal, and A. W. Wu, "Trends and variation in oral anticoagulant choice in patients with atrial fibrillation, 2010-2017," Pharmacotherapy, vol. 38, no. 9, pp. 907-920, 2018.

[23] S. Halvorsen, W. Ghanima, I. Fride Tvete et al., "A nationwide registry study to compare bleeding rates in patients with atrial fibrillation being prescribed oral anticoagulants," European Heart Journal - Cardiovascular Pharmacotherapy, vol. 3, no. 1, pp. 28-36, 2017.

[24] Y.-H. Cha, J. H. Chi, and N. M. Barbaro, "Spontaneous spinal subdural hematoma associated with low-molecular-weight heparin," Journal of Neurosurgery: Spine, vol. 2, pp. 612-613, 2005.

[25] S. Y. Chau and S. C. Tiu, "Spinal subdural haematoma: a rare complication of R E P O R T low-molecular-weight heparin therapy," Hong Kong medical journal, vol. 14, 2008.

[26] M. Payer and R. Agosti, "Spontaneous acute spinal subdural hematoma: spontaneous recovery from severe paraparesis-case report and review," Acta Neurochirurgica, vol. 152, no. 11, pp. 1981-1984, 2010.

[27] U. S. Wang, C. I. Ju, S. W. Kim, and S. H. Kim, "Spontaneous concomitant intracranial and spinal subdural hematomas in association with anticoagulation therapy," Journal of Korean Neurosurgical Society, vol. 51, no. 4, pp. 237-239, 2012.

[28] O. Akiyama, A. Kondo, and H. Arai, "The rhomboid lip: anatomy, pathology, and clinical consideration in neurosurgery," World Neurosurgery, vol. 123, pp. e252-e258, 2019.

[29] J. J. Langmayr, M. Ortler, A. Dessl, K. Twerdy, F. Aichner, and S. Felber, "Management of spontaneous extramedullary spinal haematomas: results in eight patients after MRI diagnosis and surgical decompression," Journal of Neurology, Neurosurgery, and Psychiatry, vol. 59, no. 4, pp. 442-447, 1995. 